Supporting information for

\title{
Selective Detection of Trinitrophenol by Amphiphilic Dimethylaminopyridine-Appended Zn(II)phthalocyanines at the Near-Infrared Region
}

\author{
S. Kasthuri, ${ }^{\dagger}$ Pratiksha Gawas, ${ }^{\dagger}$ Samarendra Maji, ${ }^{\dagger}$ N. Veeraiah ${ }^{\ddagger}$ and N. \\ Venkatramaiah ${ }^{*} \uparrow$ \\ ${ }^{\dagger}$ Department of Chemistry, SRM Institute of Science and Technology (SRMIST), Chennai- 603 \\ 203, India. \\ \#Department of Physics, Acharya Nagarjuna University, Nagarjuna Nagar, Guntur- 522 510, \\ Andhra Pradesh, India
}




\section{Contents}

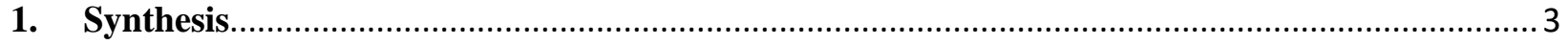

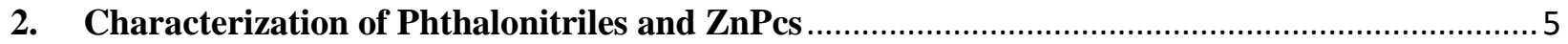

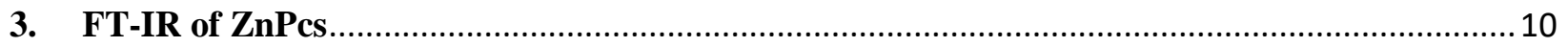

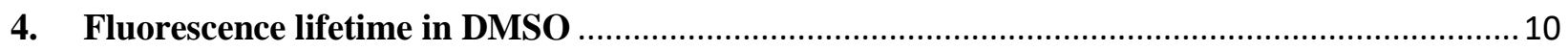

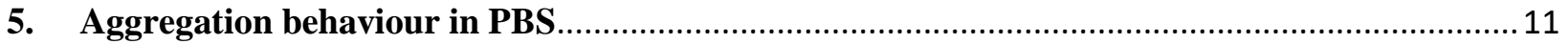

6. Stability and photostability of ZnPc derivatives .................................................................. 11

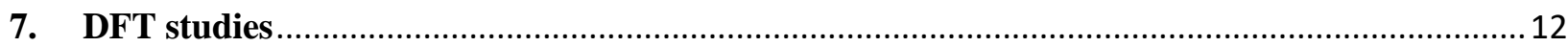

8. Chemosensing behavior ZnPes with different NACs..........................................................13

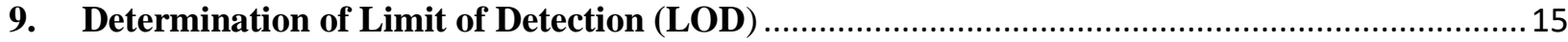

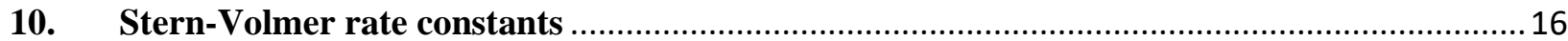

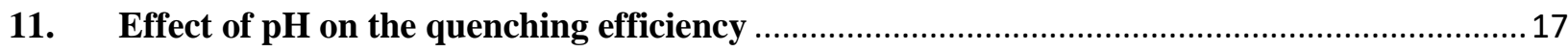

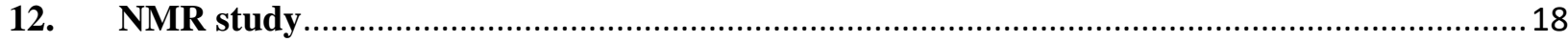

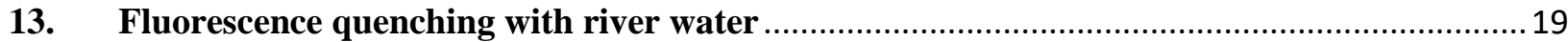

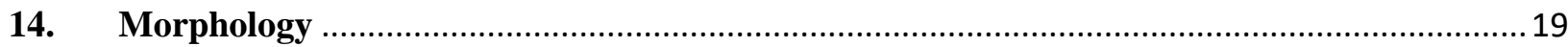

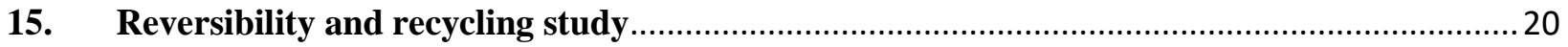




\section{Synthesis}

\section{Synthesis of 4-(4-(dimethylamino)pyridinium-1-yl)phthalonitrile monofluoride (1)}

In a $25 \mathrm{~mL}$ round bottom flask, 4-fluorophthalonitrile (146 $\mathrm{mg}, 1 \mathrm{mmol})$ and 4dimethylaminopyridine (122 mg, $1 \mathrm{mmol}$ ) was dissolved in $3 \mathrm{~mL}$ of dry DMF. The solution was stirred at $80{ }^{\circ} \mathrm{C}$ for $12 \mathrm{~h}$ under nitrogen atmosphere. The formation of light brown precipitate was observed, and the reaction mixture was cooled to ambient temperature. The obtained precipitate was filtered and washed thoroughly with chloroform and recrystallized in methanol. Yield: 206 mg (83\%). ${ }^{1} \mathrm{H}$ NMR (300.13 MHz, DMSO-d6): $\delta 8.29-8.27(\mathrm{~m}, 1 \mathrm{H}), 8.17(\mathrm{~d}, J=9 \mathrm{~Hz}, 2 \mathrm{H}), 8.03$ $(\mathrm{d}, J=2.5 \mathrm{~Hz}, 1 \mathrm{H}$, Py- $-\mathrm{H}), 8.01(\mathrm{~d}, J=2.5 \mathrm{~Hz}, 1 \mathrm{H}, \mathrm{Py}-m-\mathrm{H}), 7.03$ (d, $J=6 \mathrm{~Hz}, 1 \mathrm{H}), 3.21(\mathrm{~s}$, $\left.6 \mathrm{H}, \mathrm{N}\left(\mathrm{CH}_{3}\right)_{2}\right) .{ }^{13} \mathrm{C}$ NMR $\left(75.47 \mathrm{MHz}, \mathrm{DMSO}-d_{6}\right): \delta$ 157.4, 145.7, 140.7, 137.0, 129.2, 117.8, 116.1, 109.4, $41.5\left(\mathrm{~N}\left(\mathrm{CH}_{3}\right)_{2}\right)$. ESI-MS: m/z calculated for $\mathrm{C}_{15} \mathrm{H}_{13} \mathrm{~N}_{4}: 249.1$; found: $249.1\left(\mathrm{M}^{+}\right)$. FT-IR (KBr pellet), $v_{\max } / \mathrm{cm}^{-1}: v(\mathrm{C}-\mathrm{H})=2922-2875 \mathrm{w} ; v(\mathrm{C} \equiv \mathrm{N})=2228 \mathrm{~s} ; v(\mathrm{C}=\mathrm{C})=1595,1525$ $\mathrm{s} ; \beta(\mathrm{C}-\mathrm{H})=1458 \mathrm{vs} ; v(\mathrm{C}-\mathrm{H})=1420 \mathrm{vs} ; v(\mathrm{C}-\mathrm{C})=1382 \mathrm{~s} ; v(\mathrm{C}-\mathrm{N})=1229 \mathrm{~m} ; v(\mathrm{C}-\mathrm{N})=1024 \mathrm{~m}$; $\gamma(\mathrm{C}-\mathrm{H})=972 \mathrm{~s}, 745 \mathrm{w}$.

\section{Synthesis of 4,5-bis(4-(dimethylamino)pyridinium-1-yl)phthalonitrile dichloride (2)}

In a $25 \mathrm{~mL}$ round bottom flask, 4,5-dichlorophthalonitrile (196 mg, $1 \mathrm{mmol}$ ) and 4dimethylaminopyridine $(244 \mathrm{mg}, 2 \mathrm{mmol})$ was dissolved in $3 \mathrm{~mL}$ of anhydrous DMF. The solution was stirred at $80{ }^{\circ} \mathrm{C}$ for $12 \mathrm{~h}$ under nitrogen atmosphere. The formation of brown colored precipitate was observed, and the reaction mixture was cooled to ambient temperature. The obtained precipitate was filtered and washed thoroughly with chloroform and recrystallized in methanol. Yield: $296 \mathrm{mg}(80 \%) .{ }^{1} \mathrm{H}$ NMR (300.13 MHz, DMSO- $\left.d_{6}\right): \delta 8.88(\mathrm{~s}, 2 \mathrm{H}, \alpha-\mathrm{H}), 8.38$ $(\mathrm{d}, J=7.5 \mathrm{~Hz}, 4 \mathrm{H}, \mathrm{Py}-o-\mathrm{H}), 7.21(\mathrm{~d}, J=7.5 \mathrm{~Hz}, 4 \mathrm{H}, \mathrm{Py}-m-\mathrm{H}), 3.27\left(\mathrm{~s}, 12 \mathrm{H}, \mathrm{N}\left(\mathrm{CH}_{3}\right)_{2}\right) .{ }^{13} \mathrm{C} \mathrm{NMR}$ (75.47 MHz, DMSO- $\left.d_{6}\right): \delta 156.2,141.3,140.0,134.3,117.1,114.1,107.7,40.45\left(-\mathrm{N}_{(}\left(\mathrm{CH}_{3}\right)_{2}\right.$. ESI-MS: $\mathrm{m} / \mathrm{z}$ calculated for $\mathrm{C}_{22} \mathrm{H}_{22} \mathrm{~N}_{6}$ : 370.19; found: $370.2\left(\mathrm{M}^{+}\right)$. FT-IR ( $\mathrm{KBr}$ pellet), $v_{\max } / \mathrm{cm}^{-1}: v(\mathrm{C}-\mathrm{H})=2932-2880 \mathrm{w} ; v(\mathrm{C} \equiv \mathrm{N})=2224 \mathrm{~s} ; v(\mathrm{C}=\mathrm{C})=1593,1521 \mathrm{~s} ; \beta(\mathrm{C}-\mathrm{H})=1456 \mathrm{vs} ;$ $v(\mathrm{C}-\mathrm{H})=1423 \mathrm{vs} ; v(\mathrm{C}-\mathrm{C})=1380 \mathrm{~s} ; v(\mathrm{C}-\mathrm{N})=1224 \mathrm{~m} ; v(\mathrm{C}-\mathrm{N})=1023 \mathrm{~m} ; \gamma(\mathrm{C}-\mathrm{H})=970 \mathrm{~s}, 743 \mathrm{w}$. 


\section{Synthesis of 2,9(10),16(17),23(24)-Tetrakis(4-(dimethylamino)pyridinium-1- yl)phthalocyaninatozinc(II): ZnPc1}

A mixture of phthalonitrile, 1 (268 $\mathrm{mg}, 1 \mathrm{mmol})$, anhydrous $\mathrm{ZnCl}_{2}(68 \mathrm{mg}, 0.5 \mathrm{mmol})$ were dissolved in 2-(dimethylamino) ethanol (DMAE) $(1 \mathrm{~mL})$ in a sealed glass tube and purged with $\mathrm{N}_{2}$ gas. Catalytic amount of DBU $(50 \mu \mathrm{L})$ was added under the $\mathrm{N}_{2}$ gas flow and reaction mixture was kept at $120{ }^{\circ} \mathrm{C}$ for $12 \mathrm{~h}$. During the reaction, the colour of the solution changes from colour less to green indicates the formation of $\mathrm{Zn}(\mathrm{II})$ phthalocyanine. The reaction mixture was cooled to room temperature and diluted with acetone to precipitate the product. The precipitate was washed with methanol and recrystallized in water, dried under vacuo. Yield: $169 \mathrm{mg}(63 \%) .{ }^{1} \mathrm{H}$ NMR: $\delta$ 8.24-8.18 (m, 12H, Py- $o-H$ and Pc-H), 7.95-7.86 (m, 4H, Pc-H), 7.58-7.44 (m, 4H, Pc$\mathrm{H})$, 6.97-6.90 (m, 8H, Py-m-H), $3.13\left(\mathrm{~s}, 24 \mathrm{H}, \mathrm{N}\left(\mathrm{CH}_{3}\right)_{2}\right)$. MALDI-TOF MS: m/z found: 268.10730 $[\mathrm{M}+1]^{4+}$. FT-IR $(\mathrm{KBr}$ pellet $), v_{\max } / \mathrm{cm}^{-1}: v(\mathrm{O}-\mathrm{H}$, water $)=3384$ broad, $v(\mathrm{C}-\mathrm{H})=3077-$ $2930, v(C=C)=1651-1579$ vs, $v(C-C)_{\text {isoindole }}=1392 \mathrm{~m} ; v(\mathrm{C}-\mathrm{N})=1216 \mathrm{~m}, \beta(\mathrm{C}-\mathrm{H})=1104 \mathrm{w} ; v(\mathrm{C}-$ $\mathrm{N})_{\text {pyrrole }}=1053 ; \gamma(\mathrm{C}-\mathrm{H})=816,739 \mathrm{~m}$.

\section{Synthesis of 2,3,9,10,16,17,23,24-Octakis(4-(dimethylamino)pyridinium)phthalocyaninato zinc(II) ZnPc (DMAP)s: ZnPc2}

Phthalonitrile, $2(220 \mathrm{mg}, 0.5 \mathrm{mmol})$ and anhydrous $\mathrm{ZnCl}_{2}(34 \mathrm{mg}, 0.25 \mathrm{mmol})$ were taken in a sealed glass tube and $1 \mathrm{~mL}$ of DMAE $(1 \mathrm{~mL})$ was added and purged with $\mathrm{N}_{2}$ gas. Catalytic amount of DBU $(50 \mu \mathrm{L})$ was added and the reaction mixture was kept at $120{ }^{\circ} \mathrm{C}$ for $12 \mathrm{~h}$. The solution of the reaction mixture changes from colour less to green was observed. The reaction mixture was cooled to room temperature and $20 \mathrm{~mL}$ of acetone was added to precipitate the compound. The precipitate was filtered and washed with methanol and recrystallized in water, dried under vacuo. Yield: $128 \mathrm{mg}(58 \%) .{ }^{1} \mathrm{H}$ NMR: $\delta$ 8.90-8.65 (m, 4H, Pc-H), $8.27(\mathrm{~d}, J=7.5$ $\mathrm{Hz}, 8 \mathrm{H}, \mathrm{Py}-\mathrm{o}-\mathrm{H}$ ), 7.36 (broad s, 4H, Pc-H), 7.03 (d, $J=7.5 \mathrm{~Hz}, 8 \mathrm{H}, \mathrm{Py}-m-\mathrm{H}), 3.23$ (s, 48H, $\left.\mathrm{N}\left(\mathrm{CH}_{3}\right)_{2}\right)$. MALDI-TOF MS: m/z found: $265.10732\left[\mathrm{M}-(\mathrm{DMAP})_{4}\right]^{4+}$. FT-IR (KBr pellet), $v_{\max } / \mathrm{cm}^{-1}: v(\mathrm{O}-\mathrm{H}$, water $)=3448$ broad, $v(\mathrm{C}-\mathrm{H})=3064-2937, v(\mathrm{C}=\mathrm{C})=1644-1574$ vs, $v(\mathrm{C}-$ $\mathrm{C})_{\text {isoindole }}=1398,1347 \mathrm{w} ; v(\mathrm{C}-\mathrm{N})=1216 \mathrm{~s}, \beta(\mathrm{C}-\mathrm{H})=1100 \mathrm{w} ; \nu(\mathrm{C}-\mathrm{N})_{\text {pyrrole }}=1059 ; \gamma(\mathrm{C}-\mathrm{H})=816$, $746 \mathrm{~m}$. 
2. Characterization of Phthalonitriles and ZnPcs

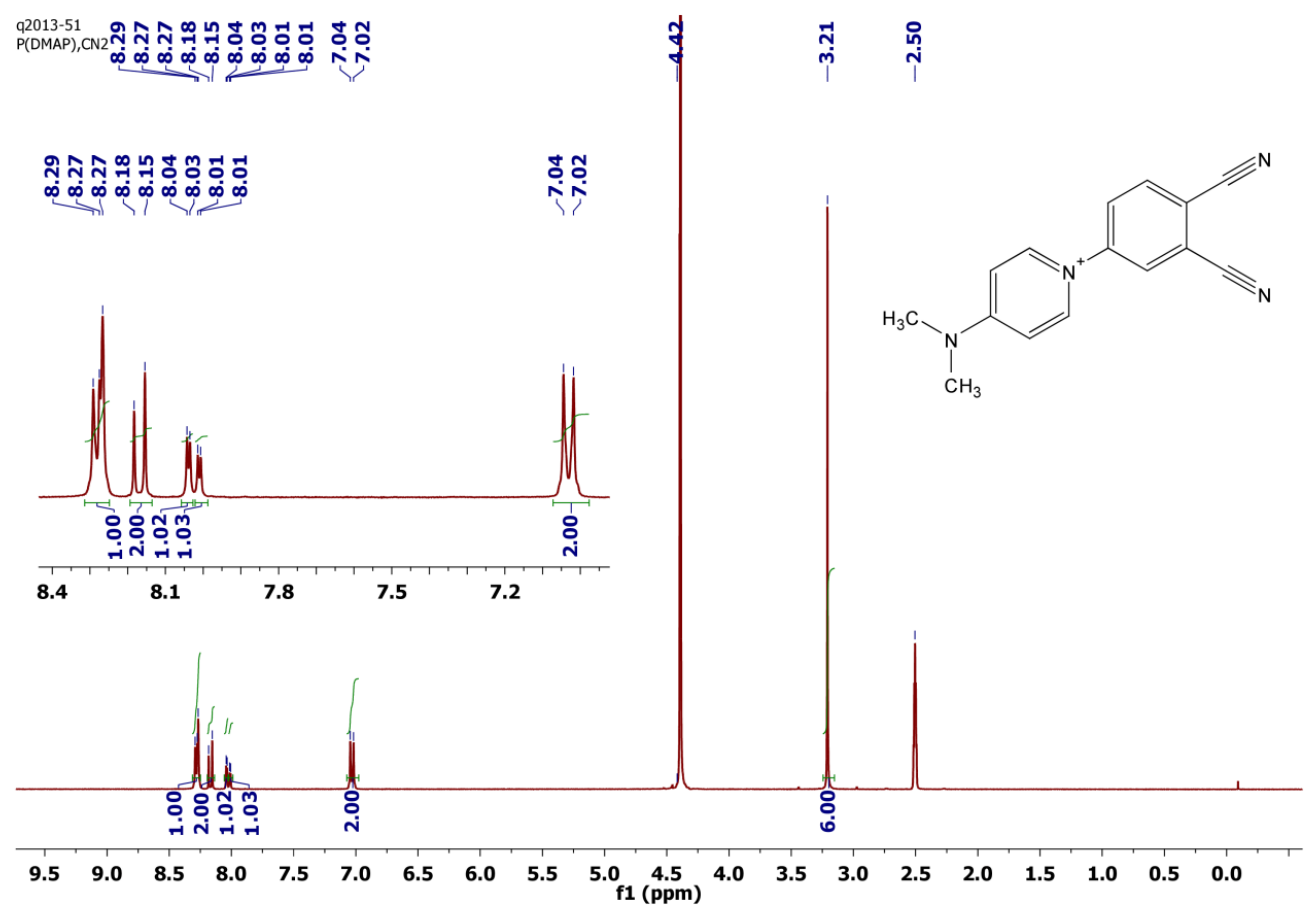

Figure S1. ${ }^{1} \mathrm{H}$ NMR $(300 \mathrm{MHz})$ spectrum of compound 1 in DMSO- $d_{6}$.

q2013-55
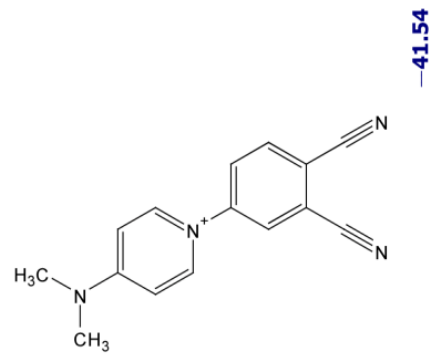

में

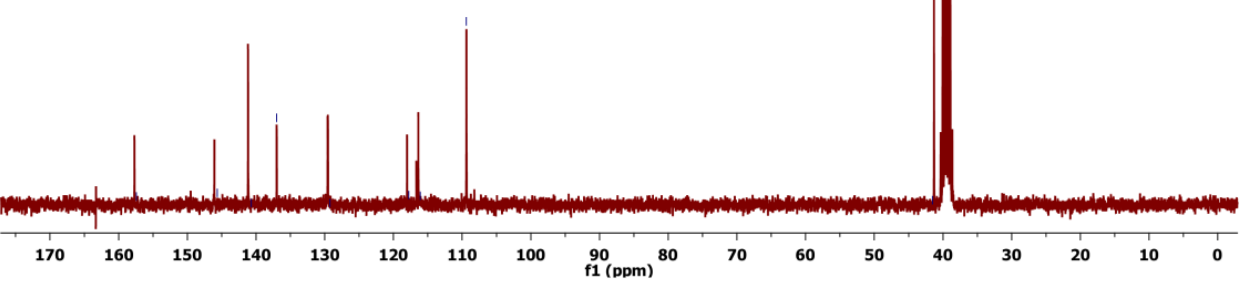

Figure S2. ${ }^{13} \mathrm{C}$ NMR (75.47 MHz) spectrum of compound 1 in DMSO-d6. 


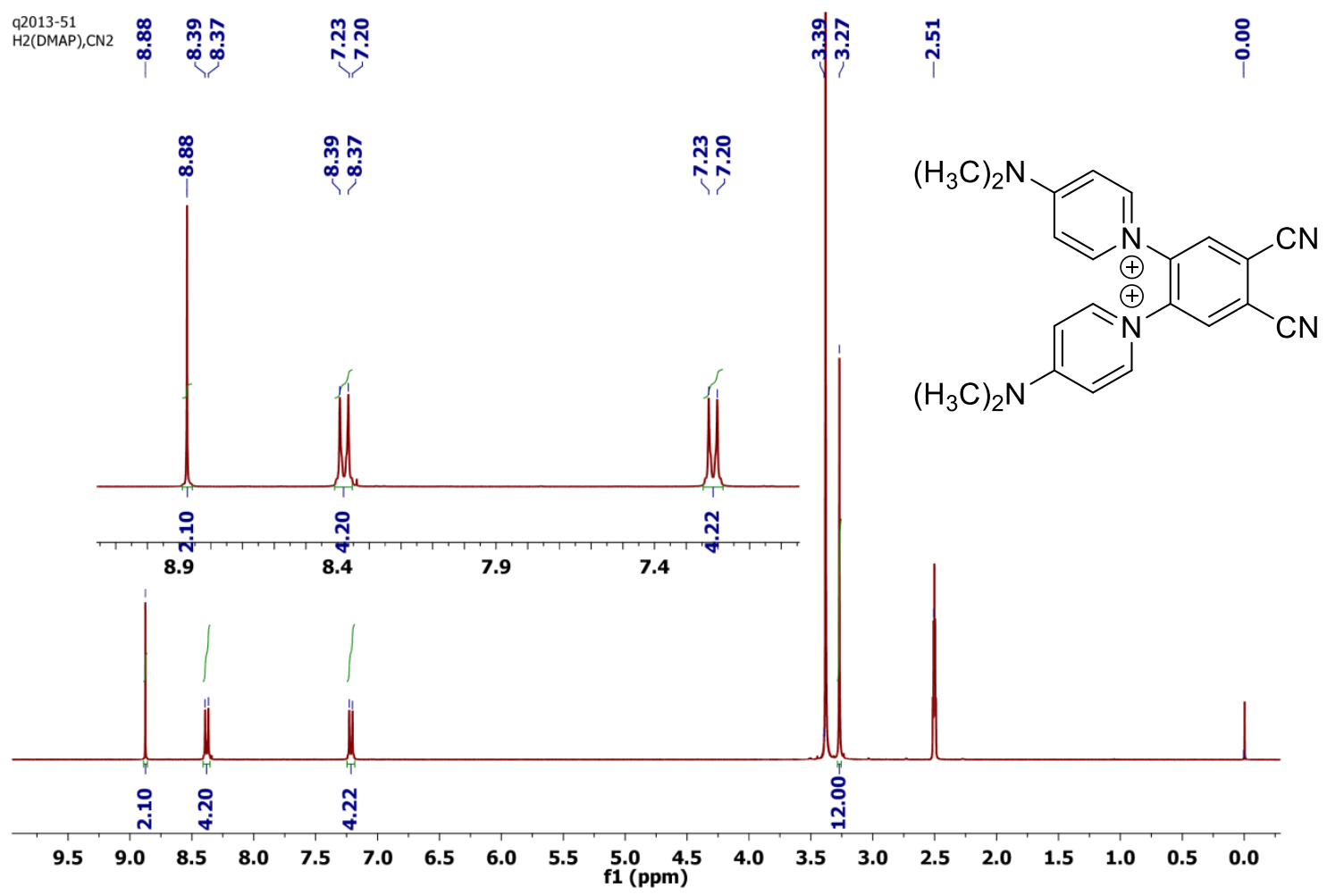

Figure S3. ${ }^{1} \mathrm{H}$ NMR (300 MHz) spectrum of compound 2 in DMSO- $d_{6}$.

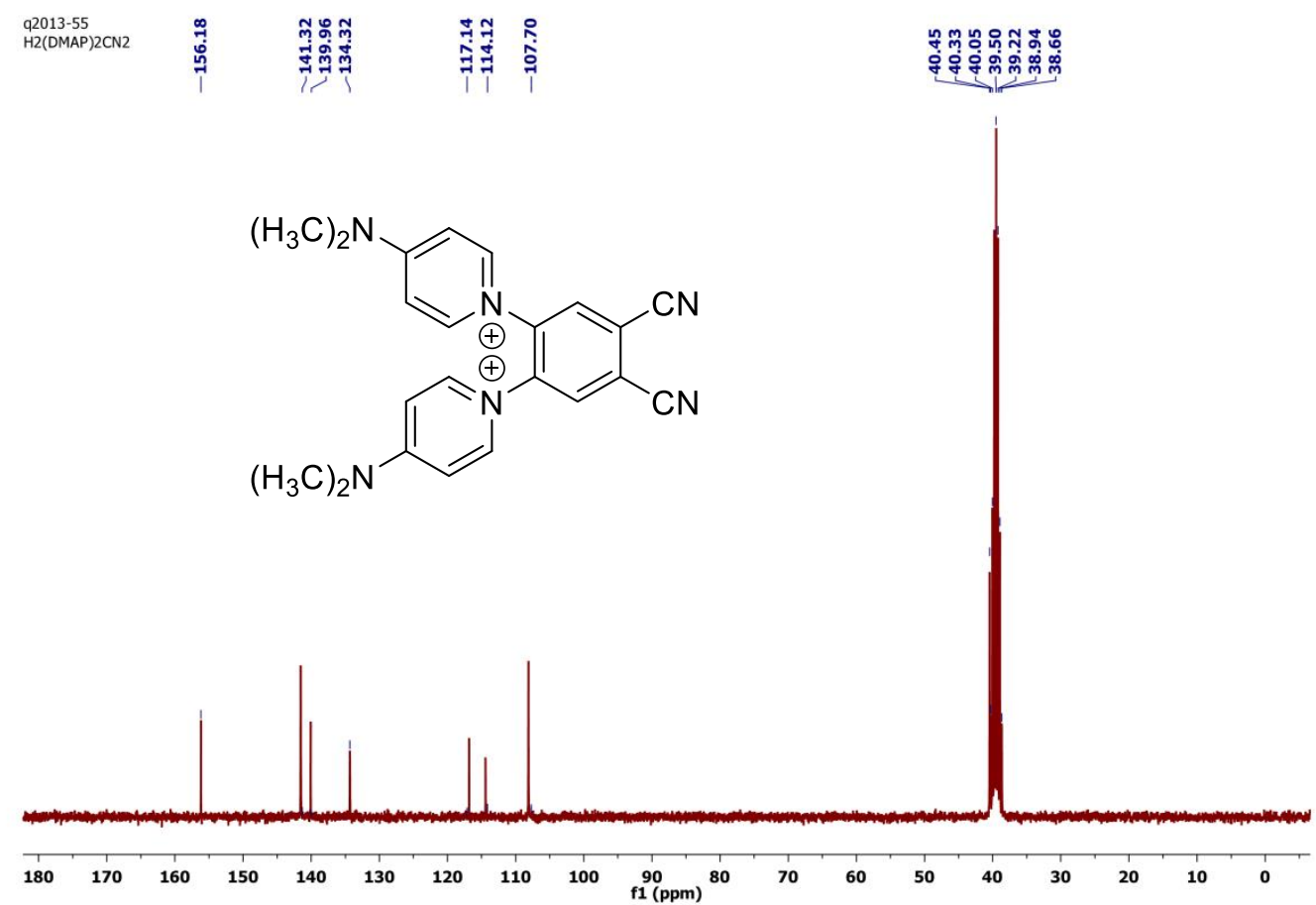

Figure S4. ${ }^{13} \mathrm{C}$ NMR $(75.47 \mathrm{MHz})$ spectrum of compound 2 in DMSO- $d_{6}$. 


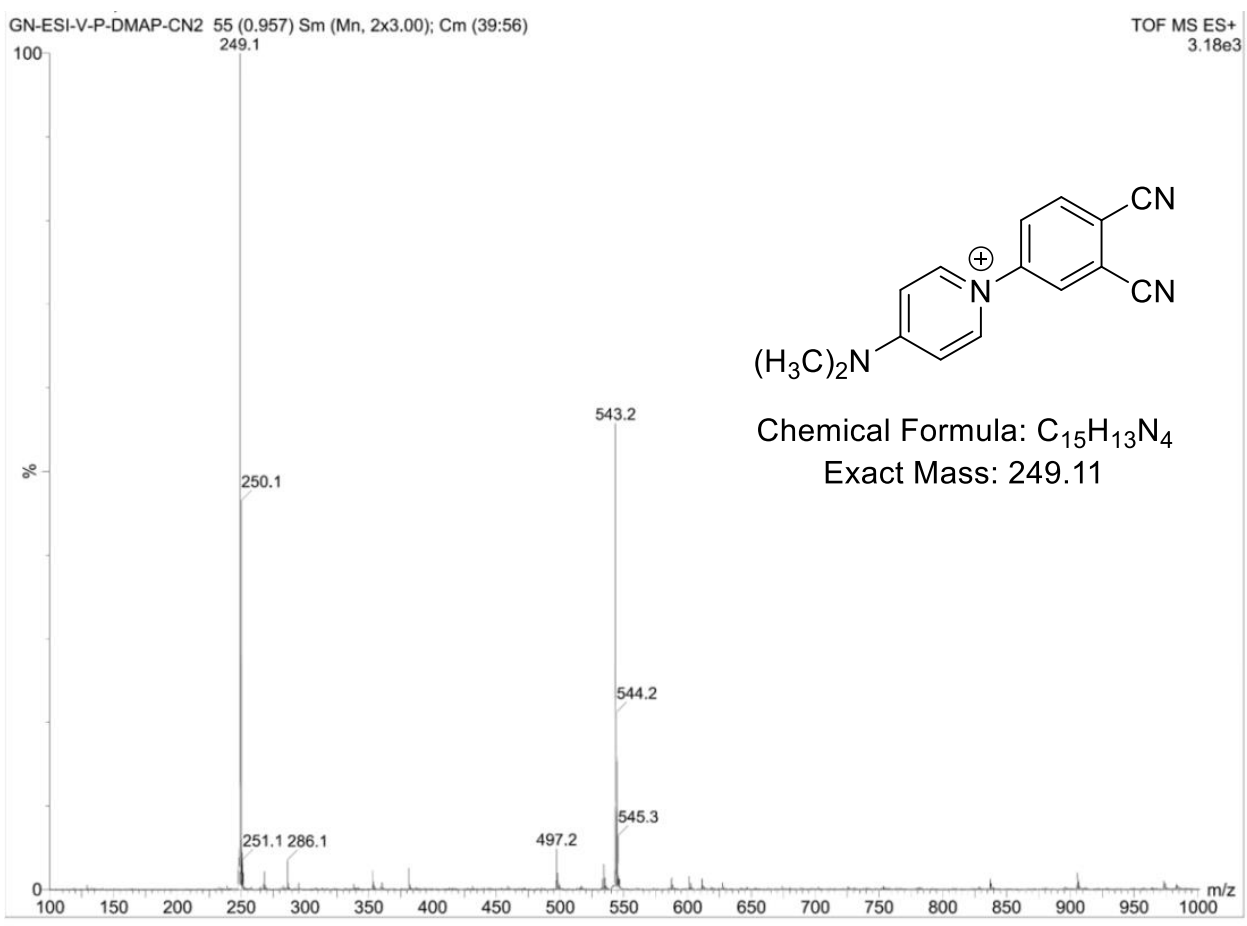

Figure S5. ESI-MS spectrum of compound 1.

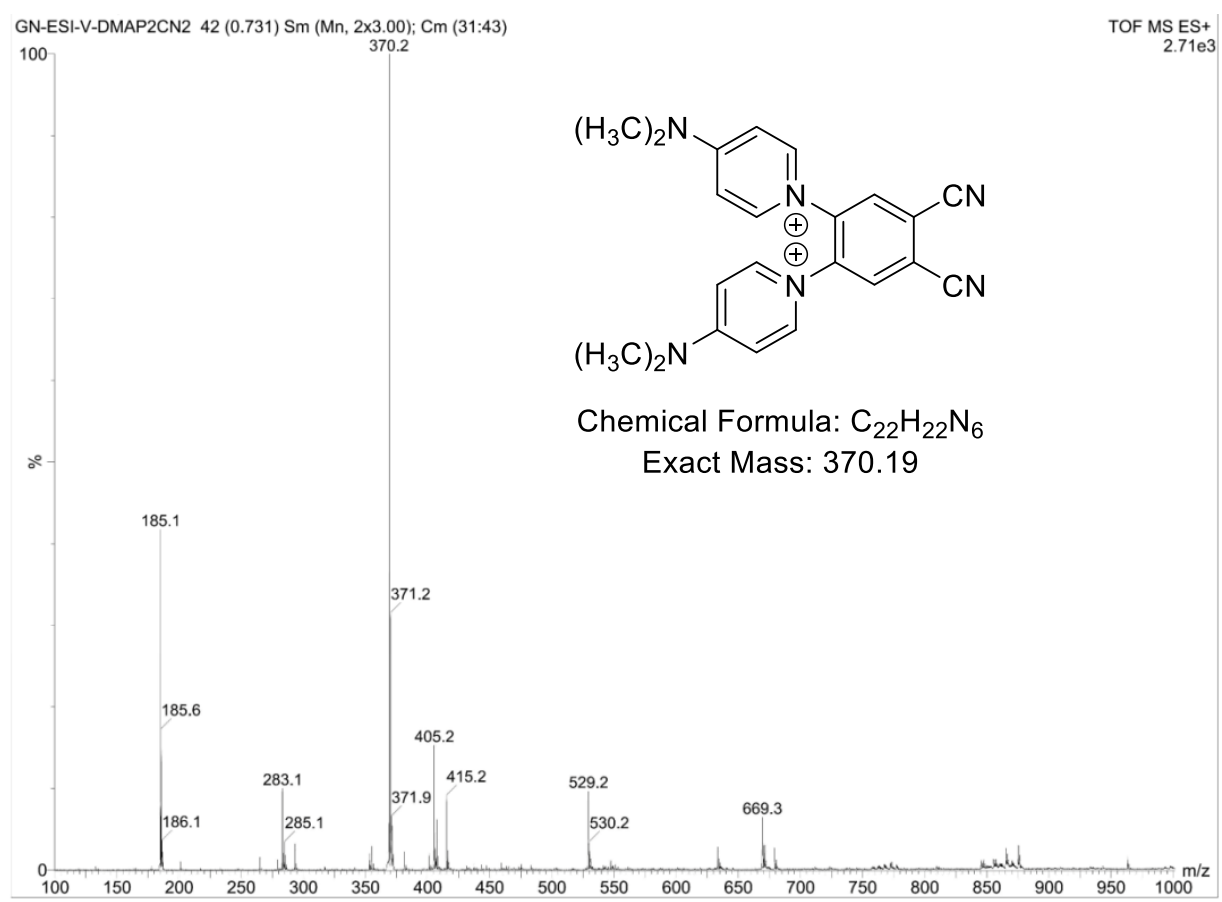

Figure S6. ESI-MS spectrum of compound 2. 


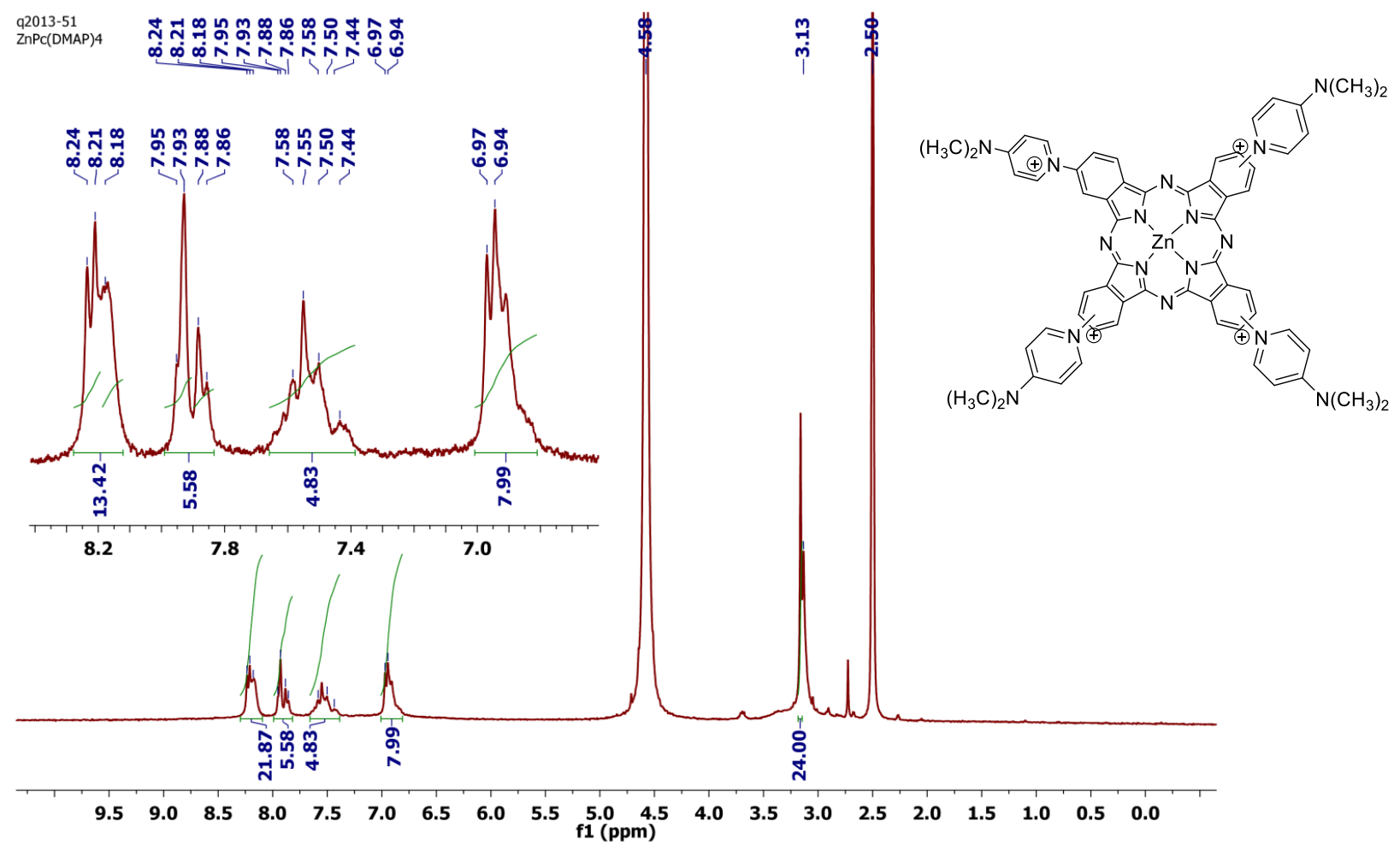

Figure S7. ${ }^{1} \mathrm{H}$ NMR (300 MHz) spectrum of compound ZnPc1 in DMSO- $d_{6}$.

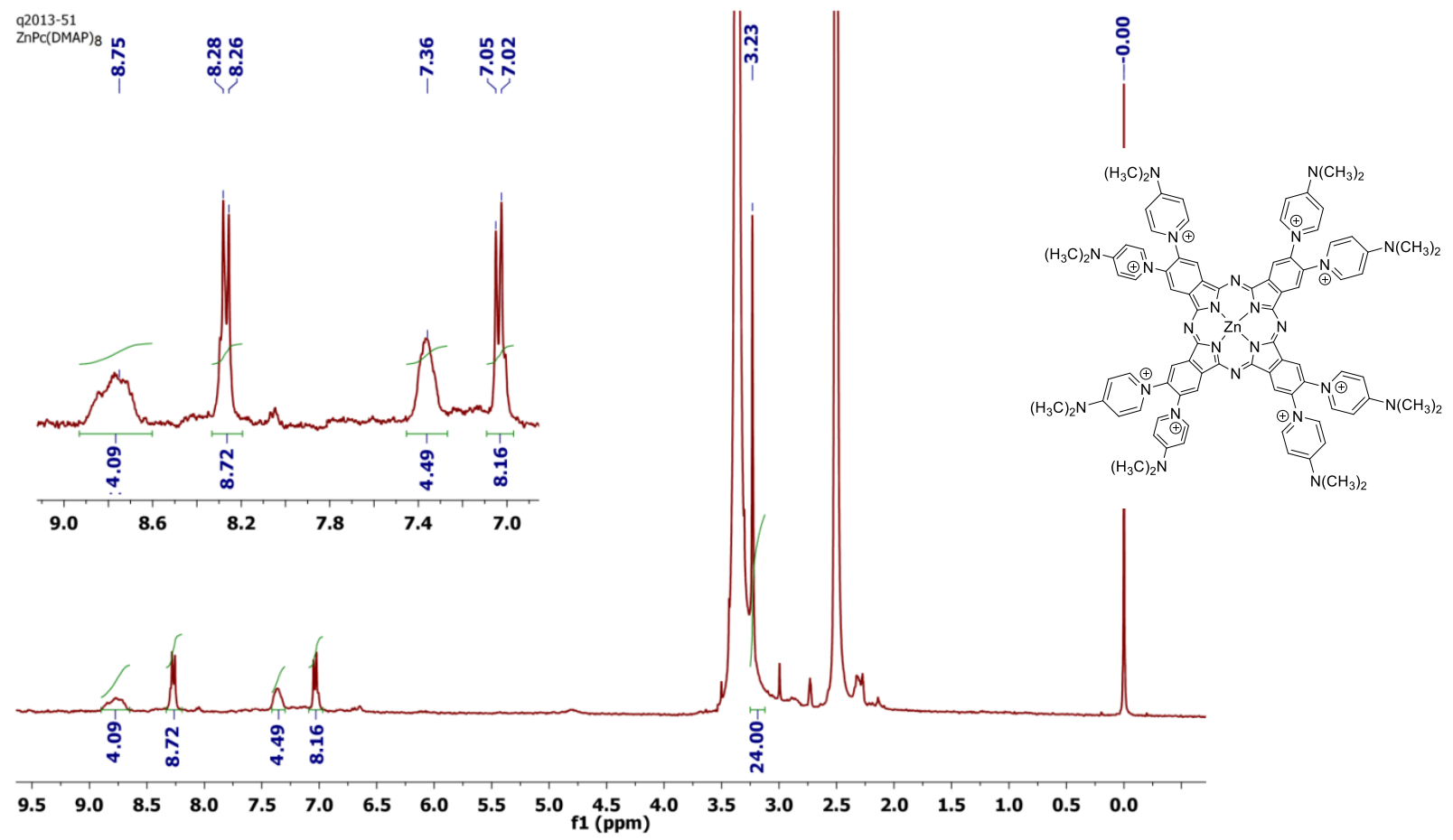

Figure S8. ${ }^{1} \mathrm{H}$ NMR (300 MHz) spectrum of compound $\mathbf{Z n P c 2}$ in DMSO- $d_{6}$. 


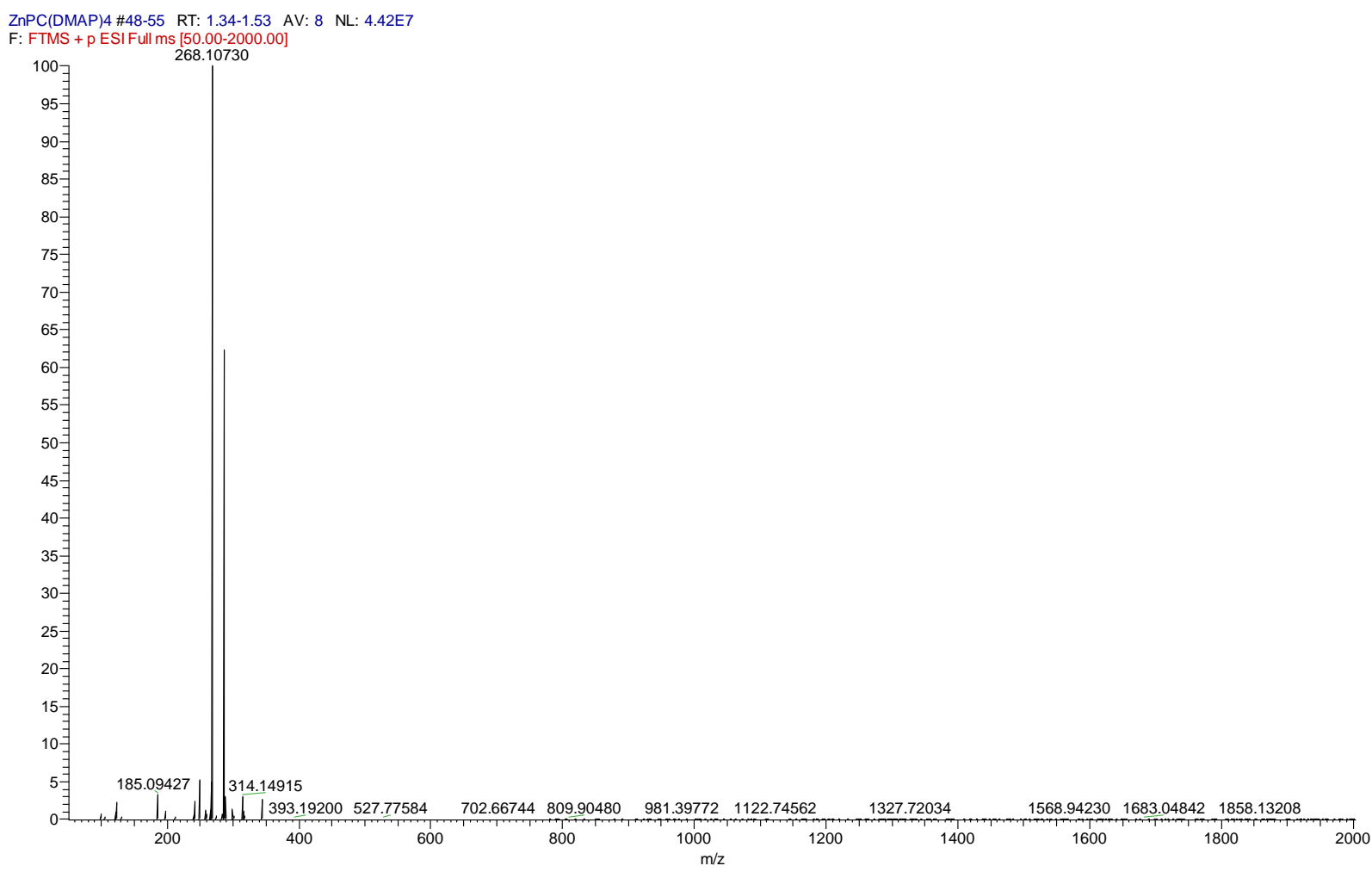

Figure S9. HR-MS spectrum of compound ZnPc1.

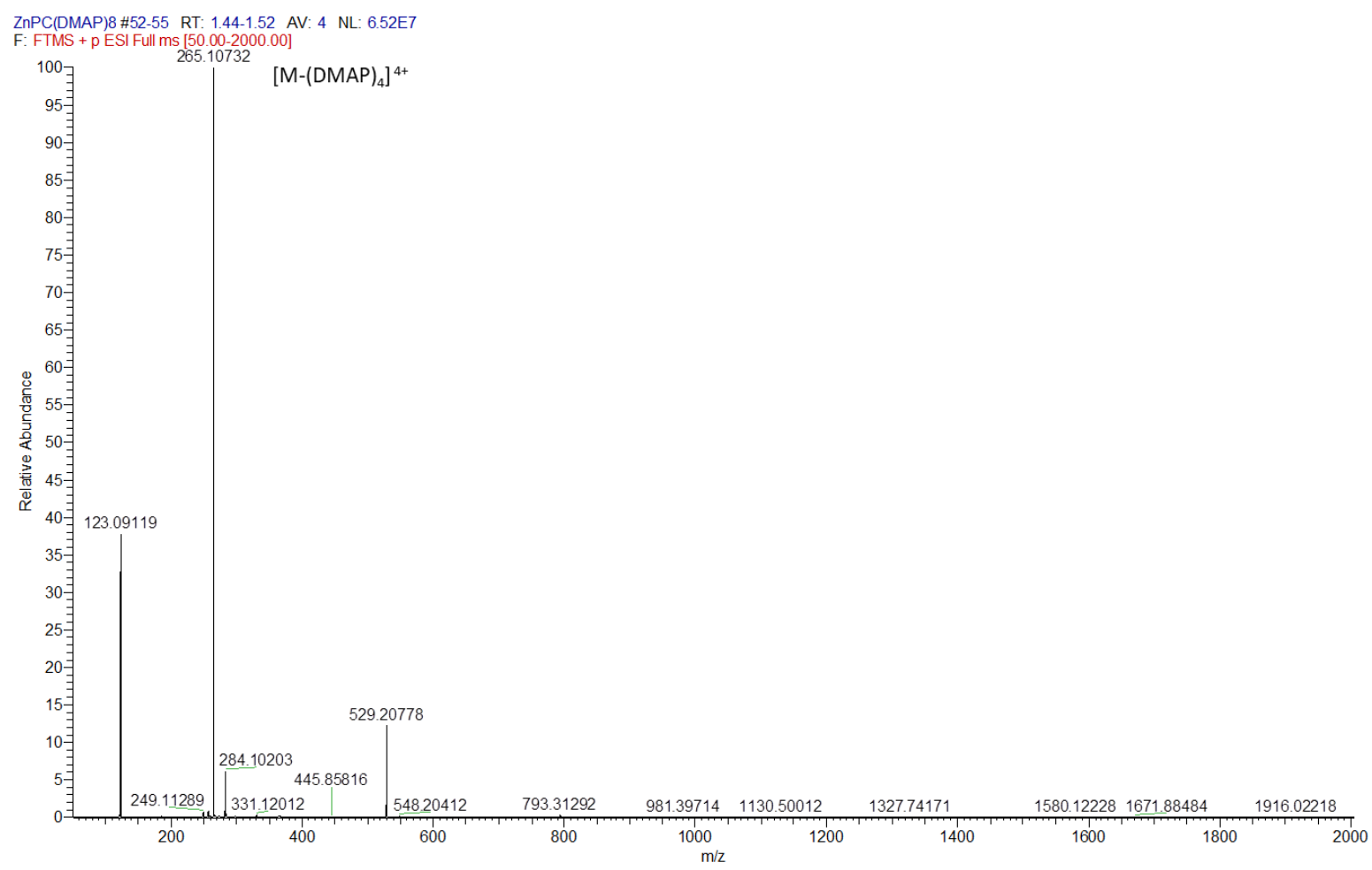

Figure S10. HR-MS spectrum of compound ZnPc2. 


\section{FT-IR of ZnPcs}

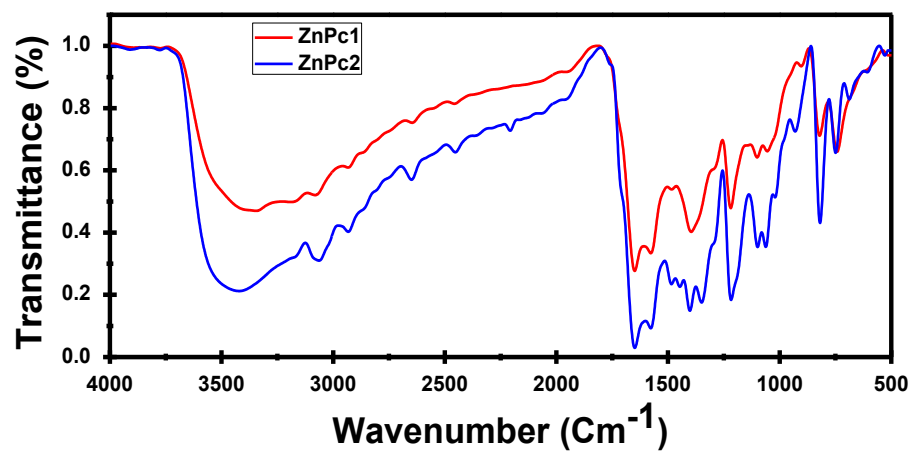

Figure S11. FT-IR spectra of ZnPcs in KBr pellet method.

\section{Fluorescence lifetime in DMSO}

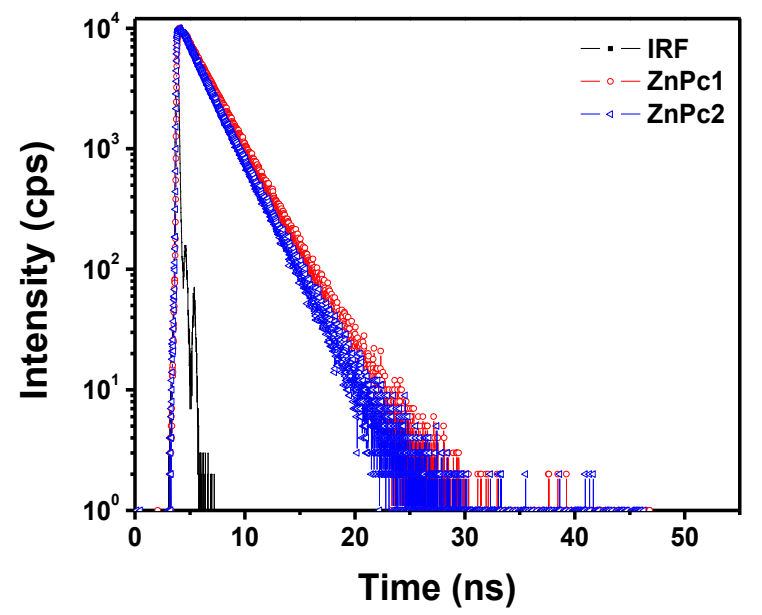

Figure S12. Fluorescence lifetime decay of ZnPcs in DMSO. 


\section{Aggregation behaviour in PBS}

(a)
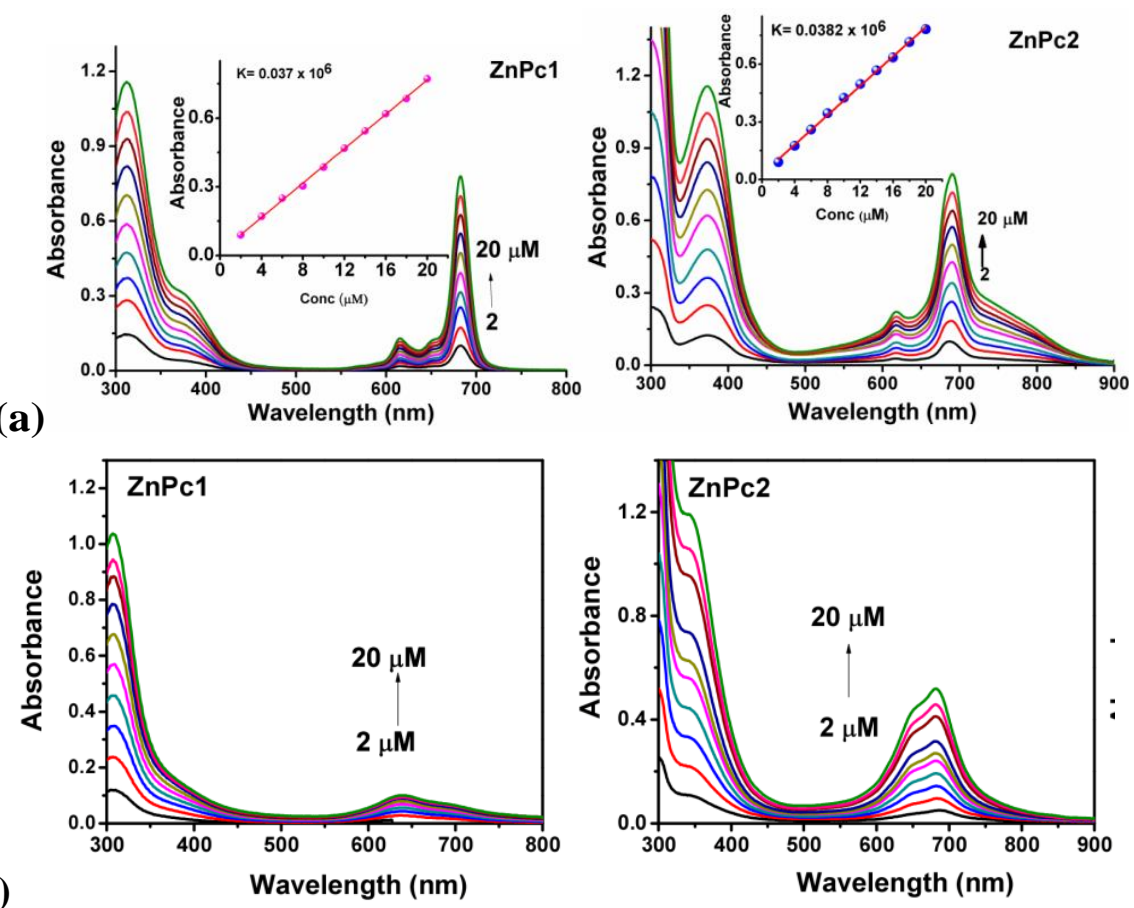

Figure S13. Change in the absorption spectra of $\mathrm{ZnPcs}$ at different concentrations (2-20 $\mu \mathrm{M})$ (a) in DMSO (b) in PBS.

\section{Stability and photostability of $\mathrm{ZnPc}$ derivatives}

Table S1. Stability and photostability of $\mathrm{ZnPc}$ derivatives in $\mathrm{PBS}$ upon irradiation for $30 \mathrm{~min}$ with red and white light.

\begin{tabular}{cccc}
\hline \multirow{2}{*}{ Compound } & \multicolumn{2}{c}{ Photostability (\%) } & \multirow{2}{*}{ Stability (\%) } \\
\cline { 2 - 3 } & Red & White & \\
\hline ZnPc1 & 91 & 94 & 97 \\
ZnPc2 & 86 & 93 & 100 \\
\hline
\end{tabular}




\section{DFT studies}

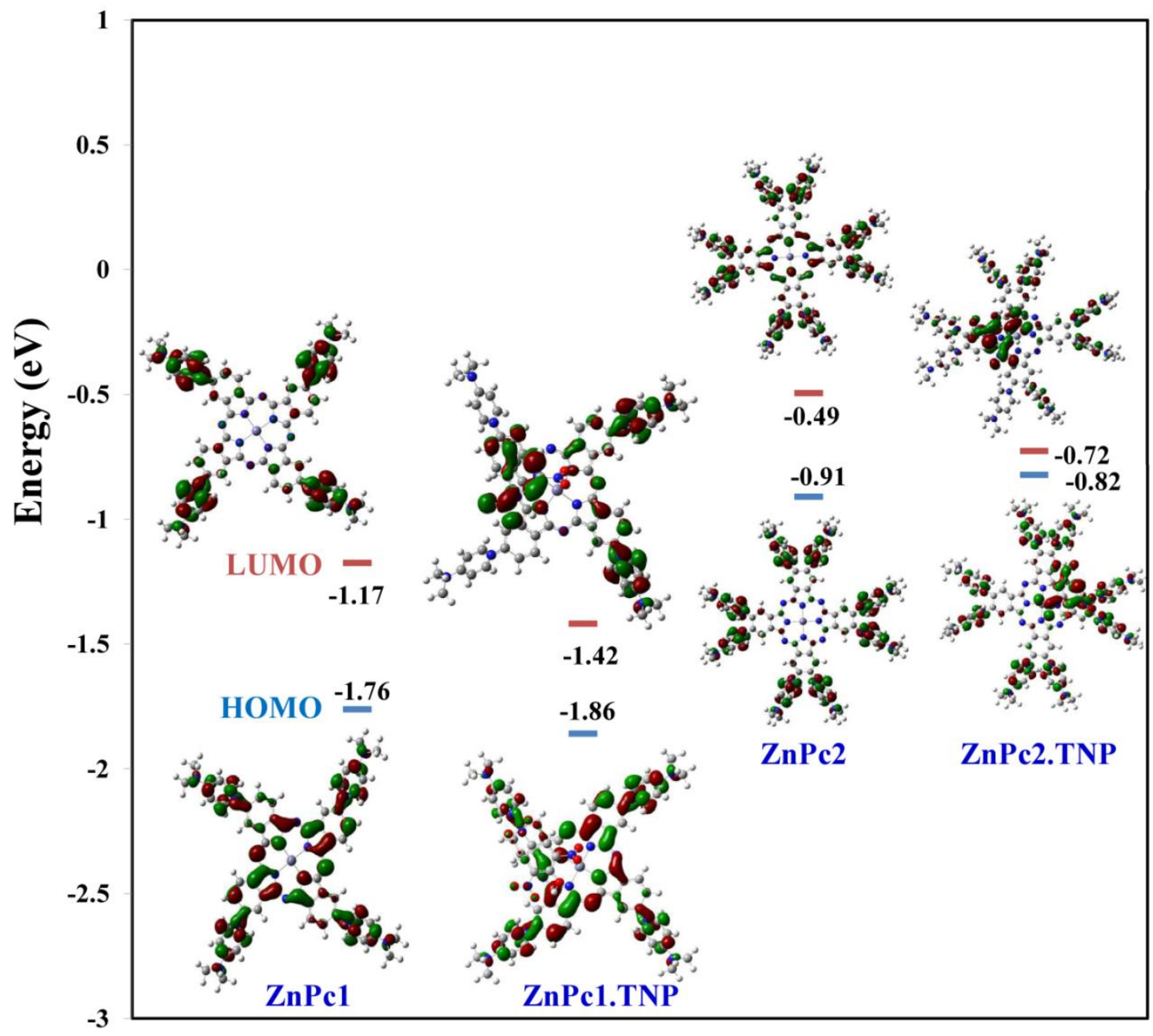

Figure. S14 Energy level diagram of ZnPcs and its adduct with TNP. 


\section{Chemosensing behavior ZnPcs with different NACs}
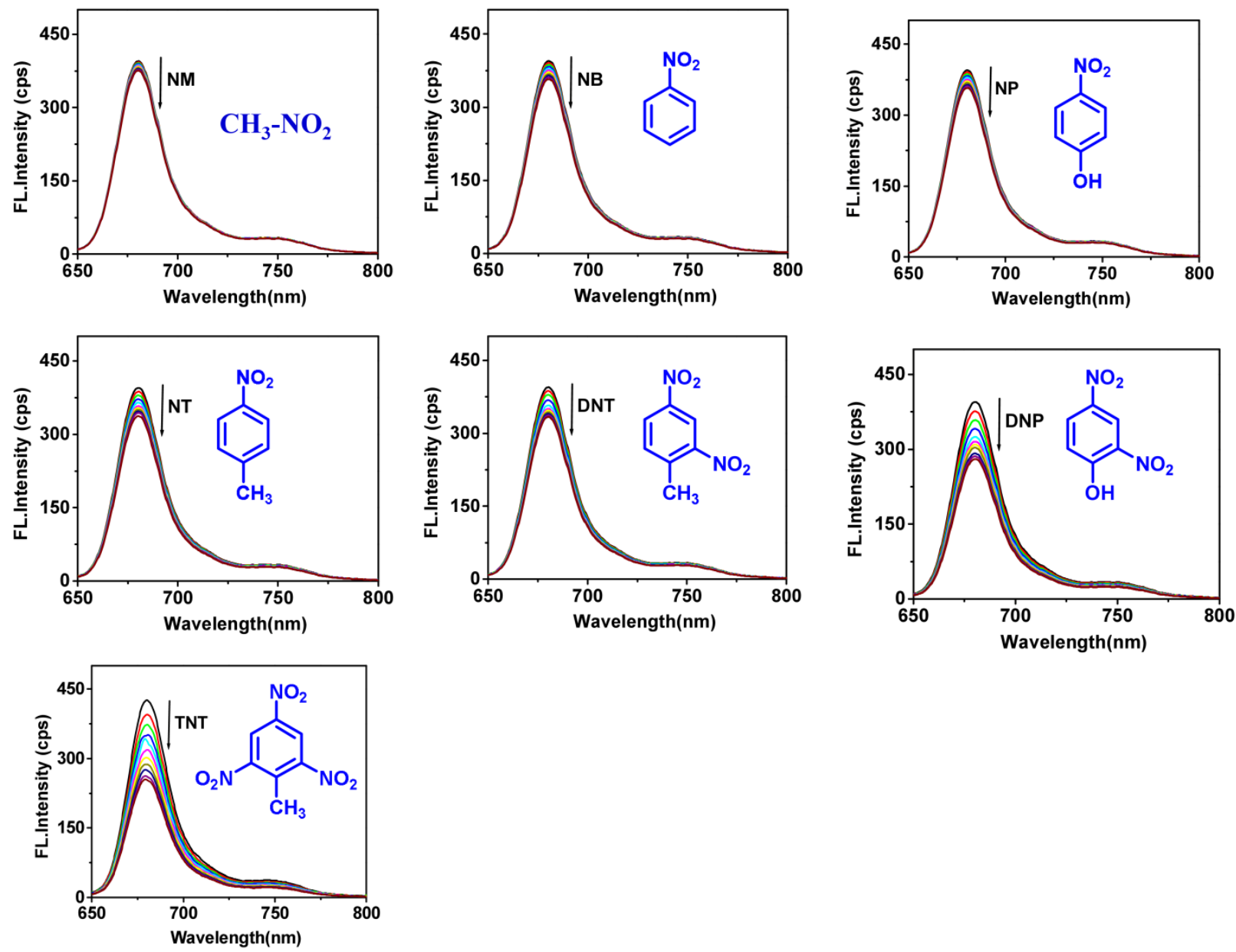

Figure $\mathrm{S} 15$. Change in the emission intensity of $\mathrm{ZnPc} 1$ upon addition of different concentrations $(0-100 \mu \mathrm{M})$ of various nitro compounds. 

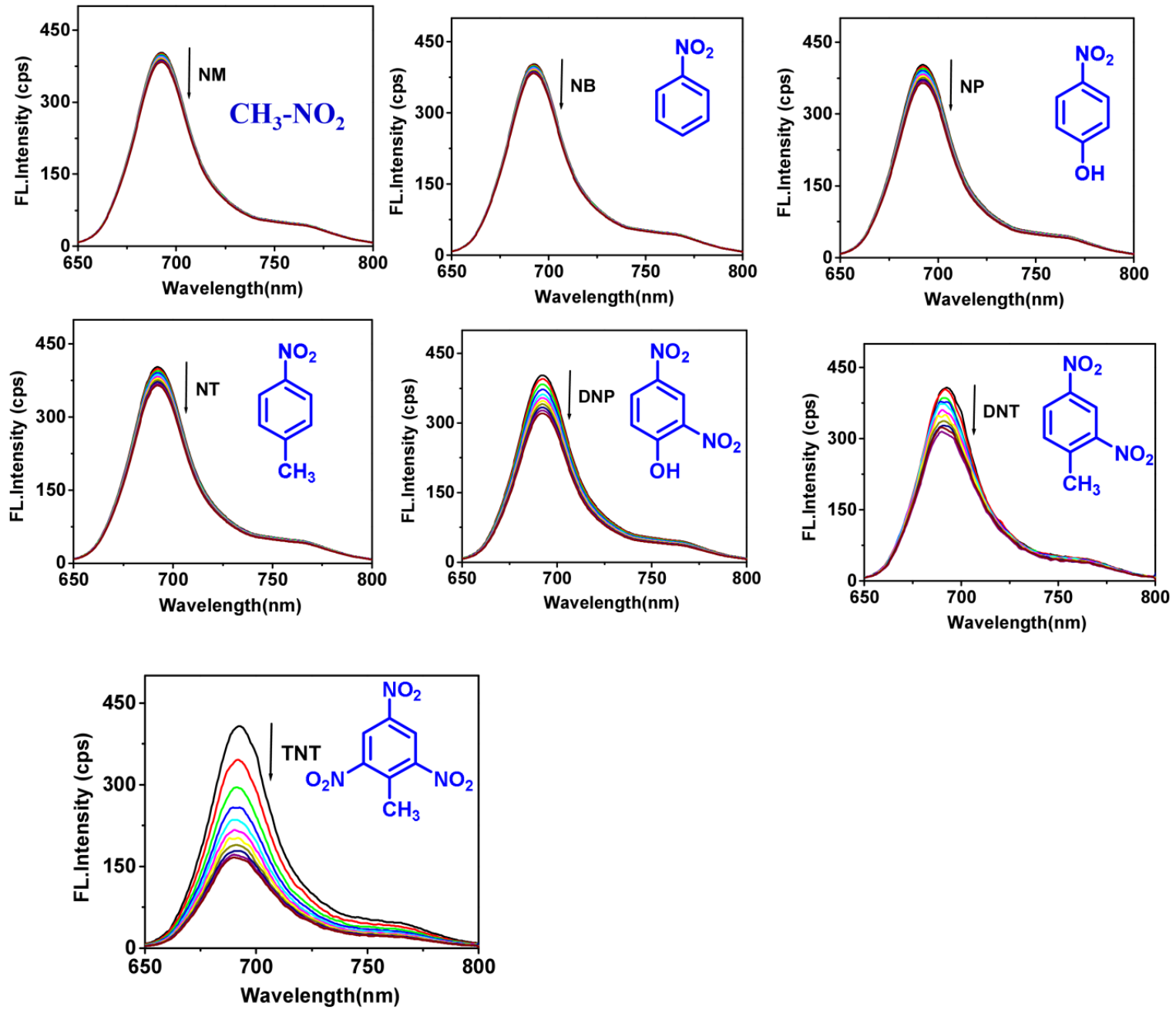

Figure S16. Change in the emission intensity of $\mathrm{ZnPc} 2$ upon addition of different concentrations $(0-100 \mu \mathrm{M})$ of various nitro compounds.

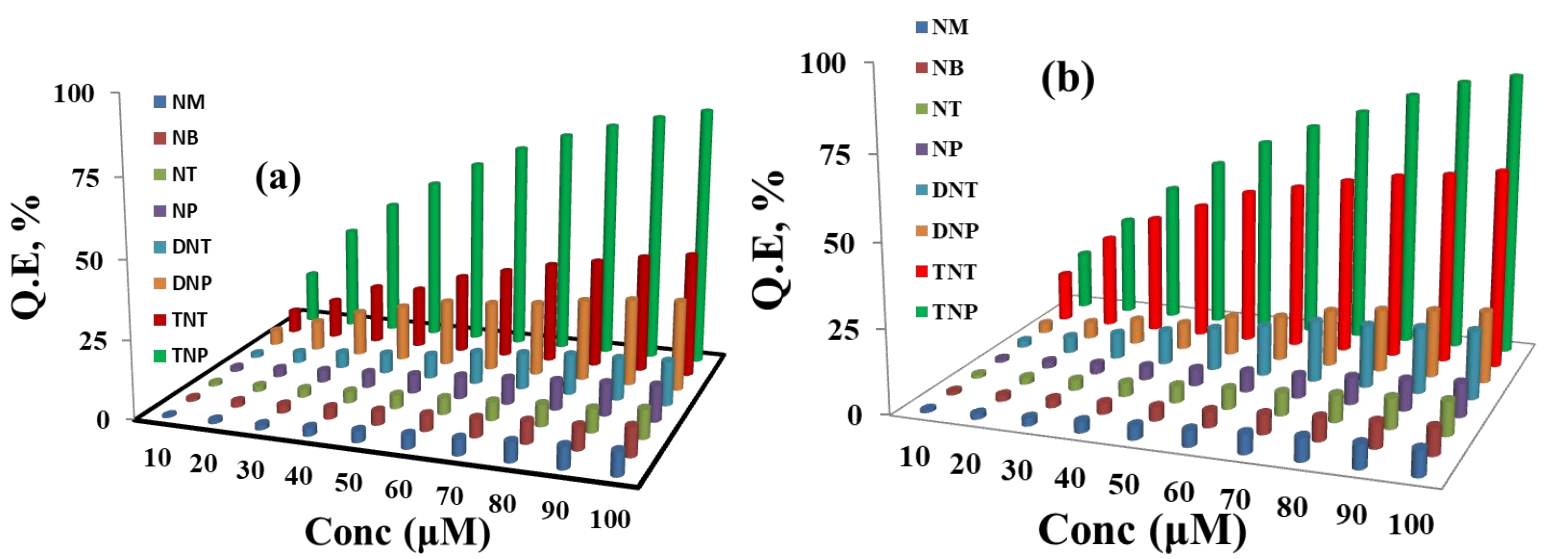

Figure S17. Change in the quenching efficiency of ZnPc1(a) and ZnPc2 (b) for different concentrations of various nitro derivatives. 


\section{Determination of Limit of Detection (LOD)}
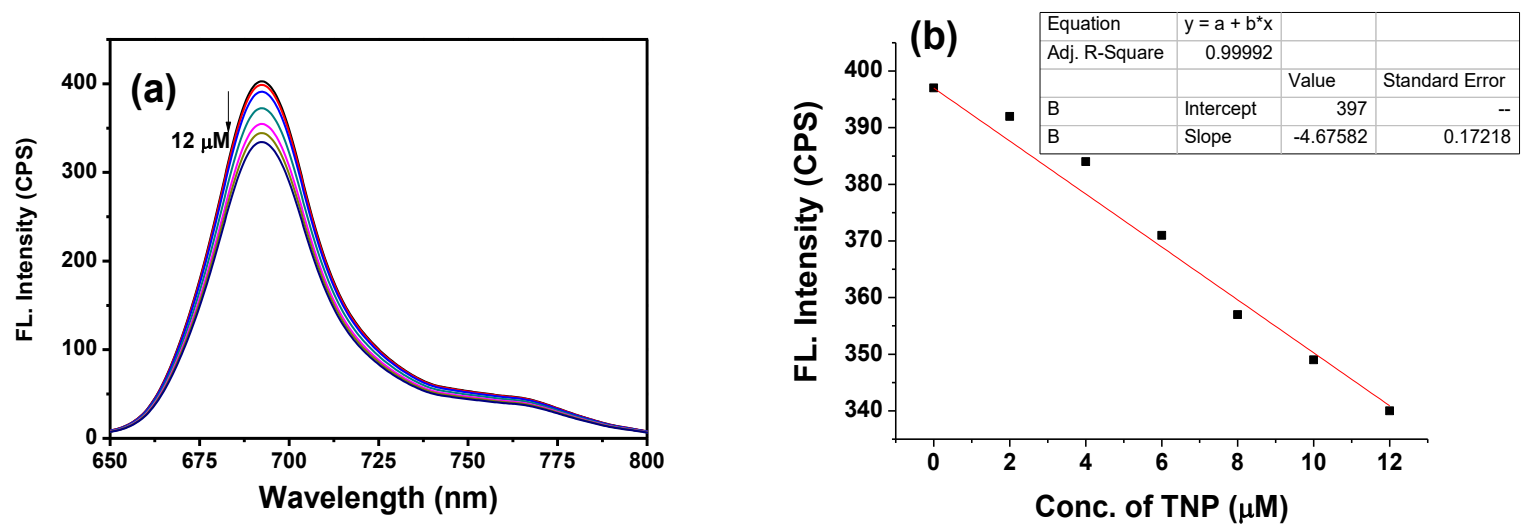

Figure S18. (a) Change in the emission spectra of ZnPc2 upon addition of different concentrations of TNP. (b) Change in the emission intensity at $696 \mathrm{~nm}$ for different concentrations of TNP.

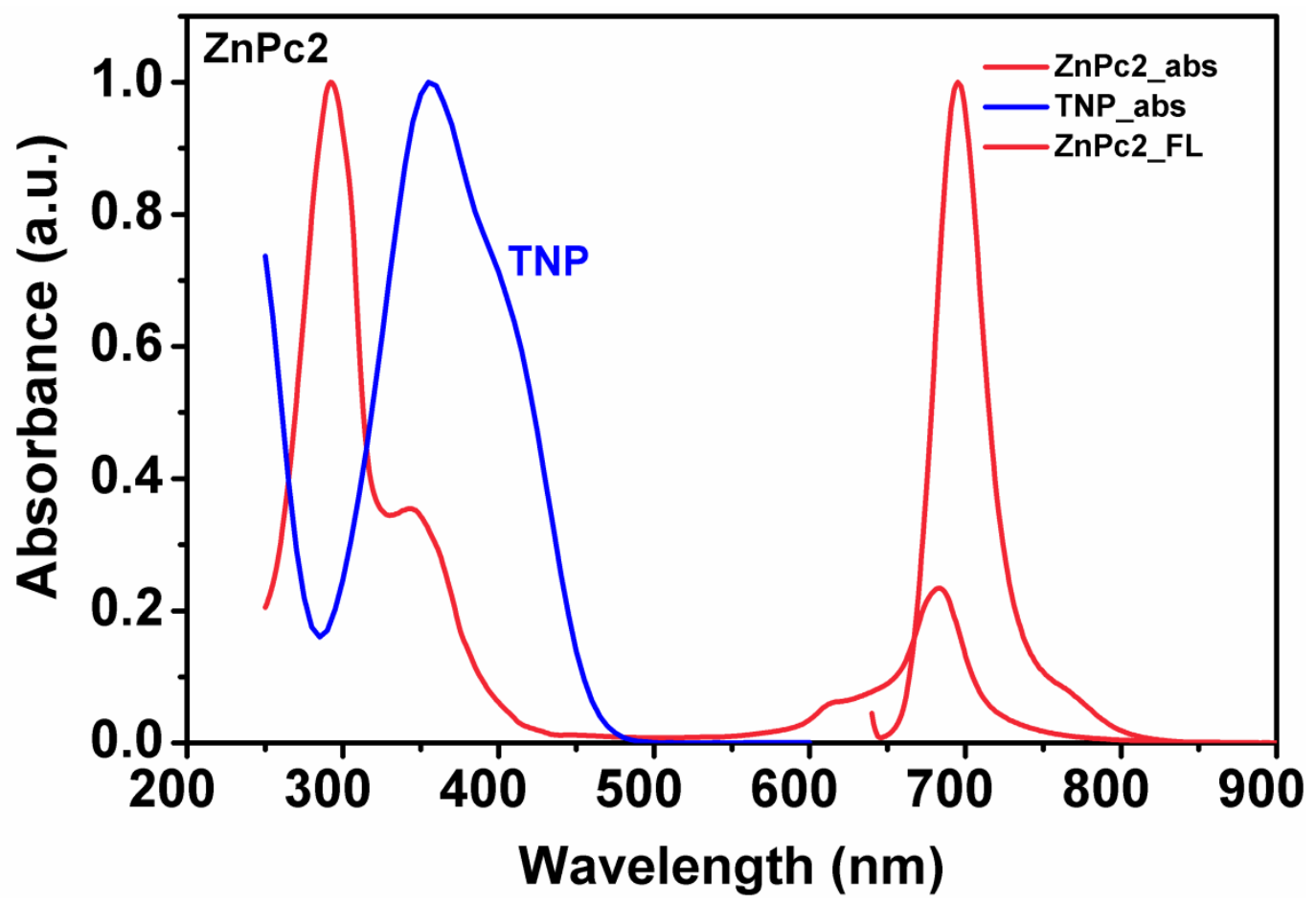

Figure S19. Spectral overlap between the absorption and emission spectra of ZnPc2 to the absorption spectra of TNP in water. 


\section{Stern-Volmer rate constants}

Table S2. Summary on the Stern-Volmer rate constants $\left(\mathrm{K}_{\mathrm{sv}}\right)$ of $\mathrm{ZnPcs}$ treated with various nitroderivatives in water.

\begin{tabular}{lll}
\hline Analyte & $\begin{array}{l}\text { ZnPc1 } \\
\left(\mathbf{1 x 1 0}^{\mathbf{6}}\right)\end{array}$ & $\begin{array}{l}\text { ZnPc2 } \\
\left(\mathbf{1 x 1 0 ^ { 6 }}\right)\end{array}$ \\
\hline NM & 0.0008 & 0.0074 \\
NB & 0.0009 & 0.0076 \\
NT & 0.0081 & 0.0094 \\
NP & 0.0112 & 0.0095 \\
DNT & 0.0153 & 0.0241 \\
DNP & 0.0393 & 0.0245 \\
TNT & 0.0592 & 0.1409 \\
TNP & 0.1636 & 0.2021 \\
\hline
\end{tabular}
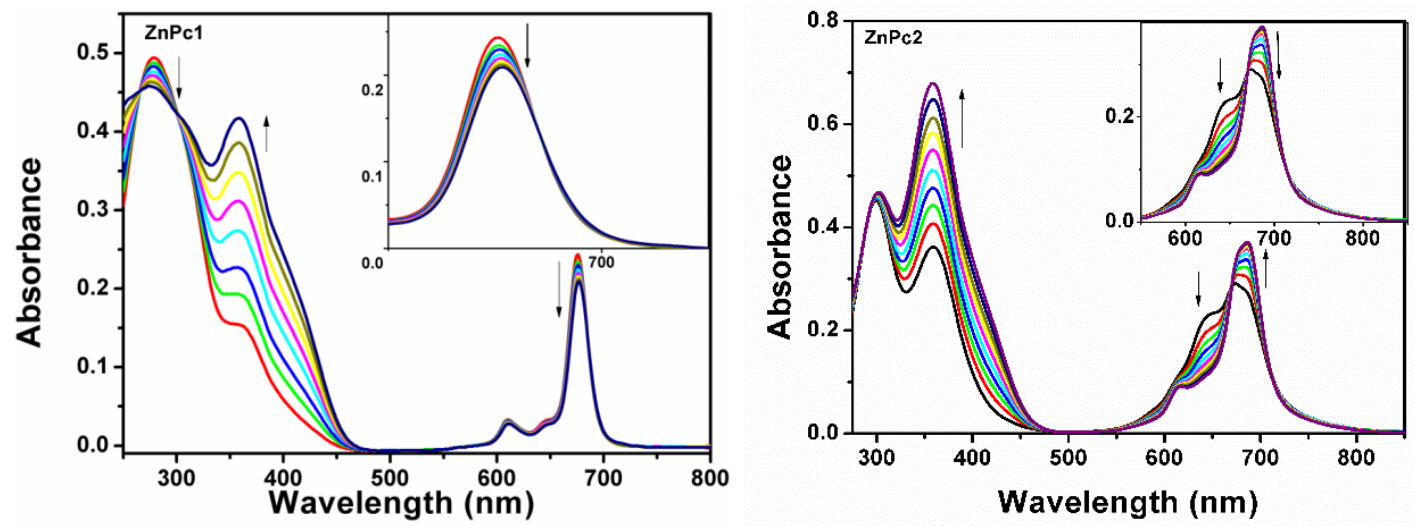

Figure S20. Changes in the absorption spectra of ZnPcs treated with different concentration of TNP in water. 


\section{Effect of $\mathrm{pH}$ on the quenching efficiency}
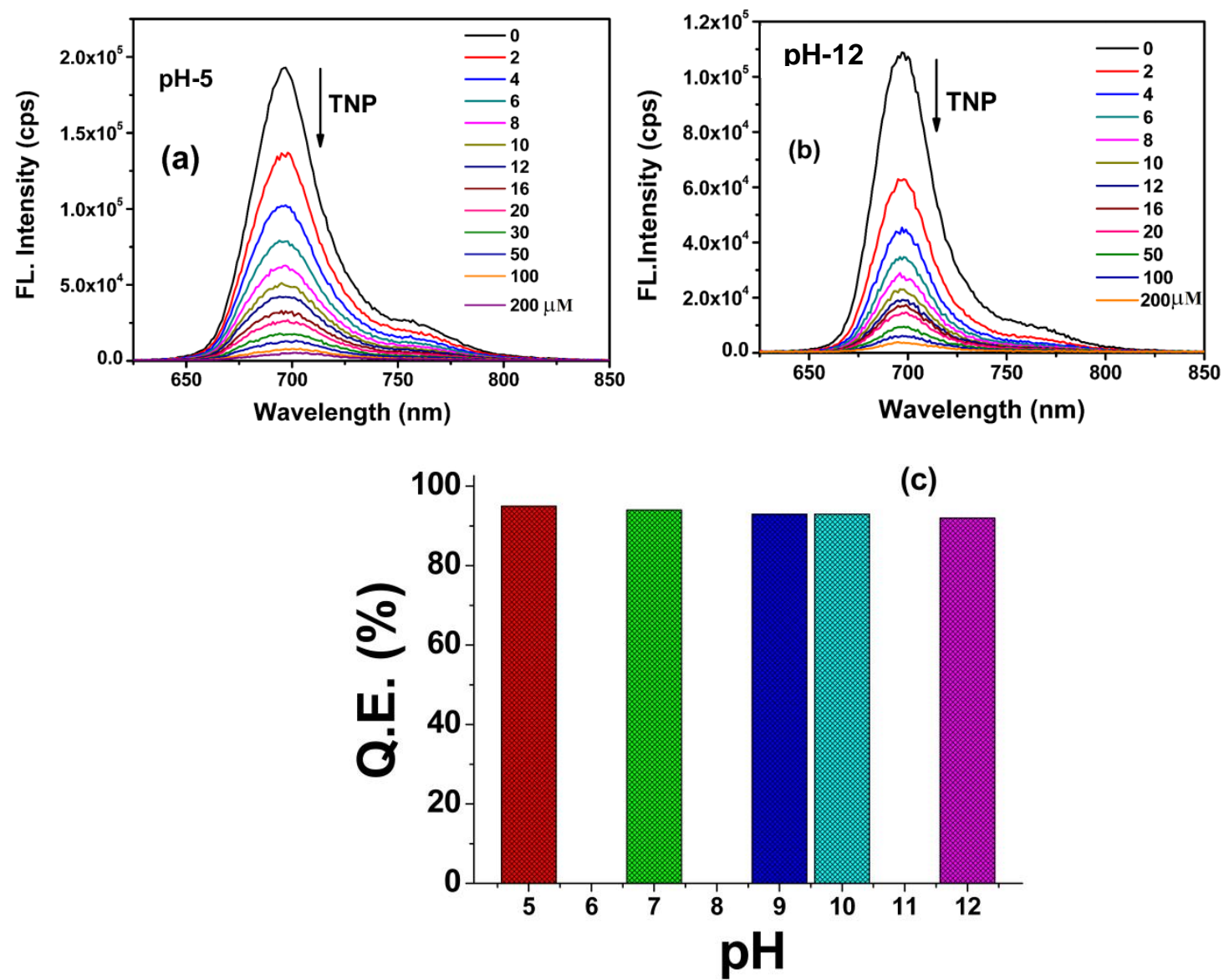

Figure S21. Change in the emission spectra of $\mathrm{ZnPc} 2$ for addition of different concentrations of $\mathrm{TNP}$ at (a) $\mathrm{pH}-5$ (b) $\mathrm{pH}-12$. (c) Comparison of quenching efficiencies of $\mathrm{ZnPc} 2$ for addition of $100 \mu \mathrm{M}$ of TNP at different $\mathrm{pH}$ regions. 


\section{NMR study}

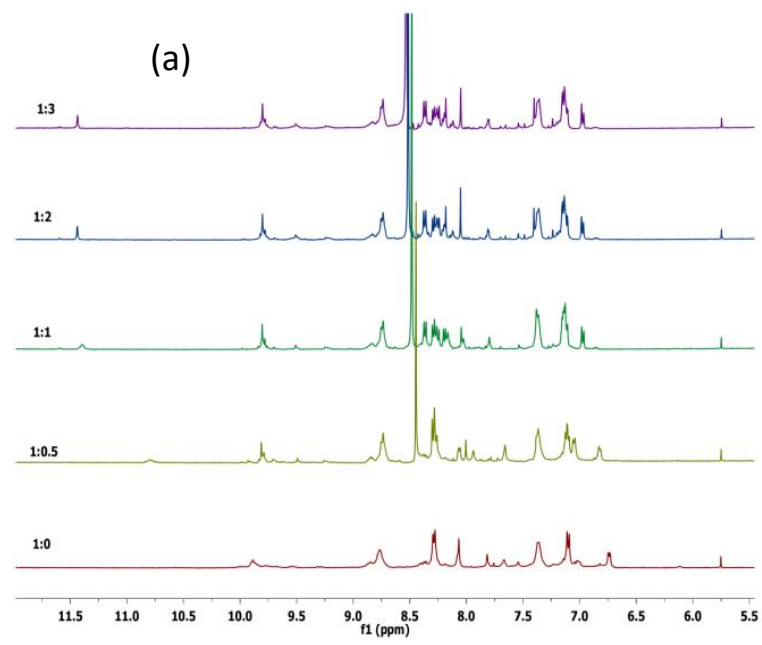

(b)

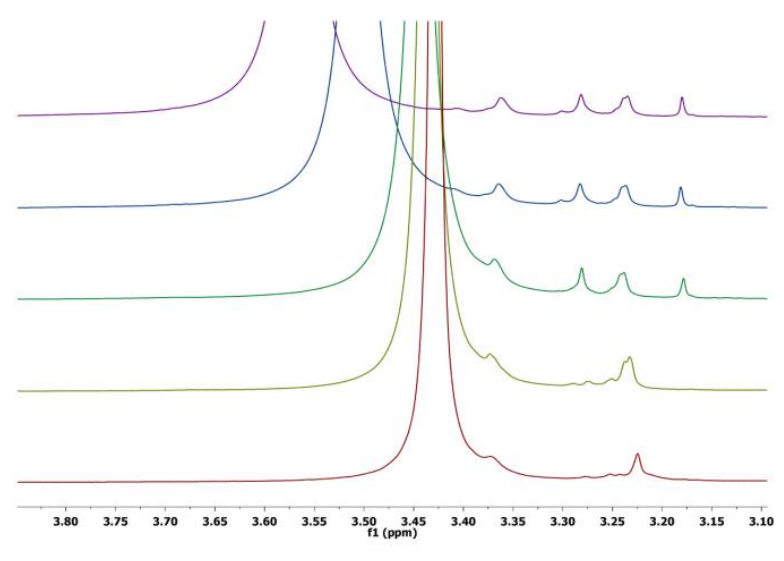

Figure S22. Partial ${ }^{1} \mathrm{H}$ NMR (400 MHz) spectra of ZnPc2 in the aromatic region upon addition of different equivalents of TNP in DMSO- $d_{6}$. (a) aromatic (b) aliphatic regions.

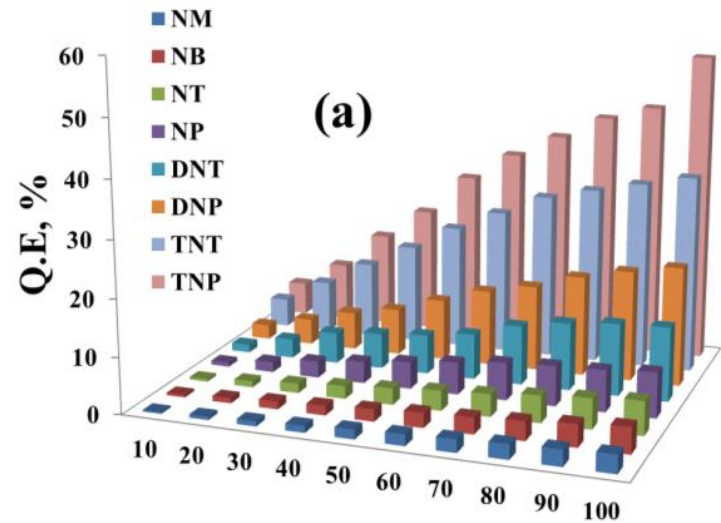

Conc, $(\mu \mathrm{M})$

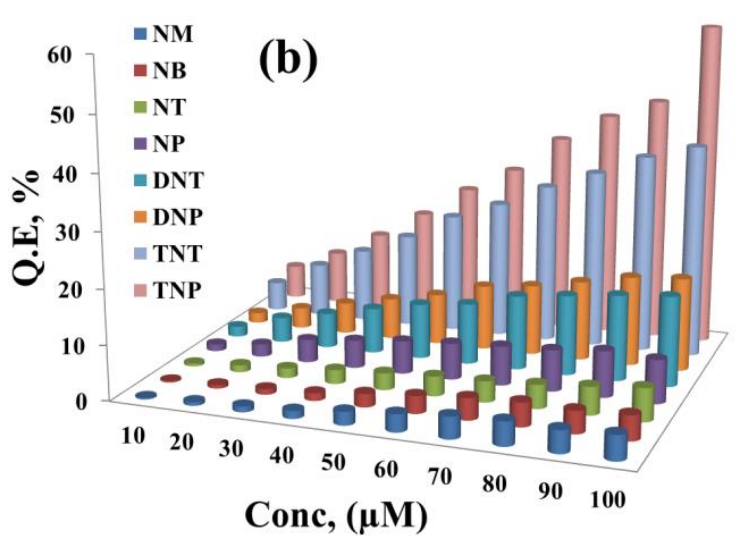

Conc, $(\mu \mathrm{M})$

Figure S23. Change in the quenching efficiency of methylated ZnPc1 (a) and ZnPc2 (b) treated with different concentrations of nitro analytes in aqueous medium. 


\section{Fluorescence quenching with river water}
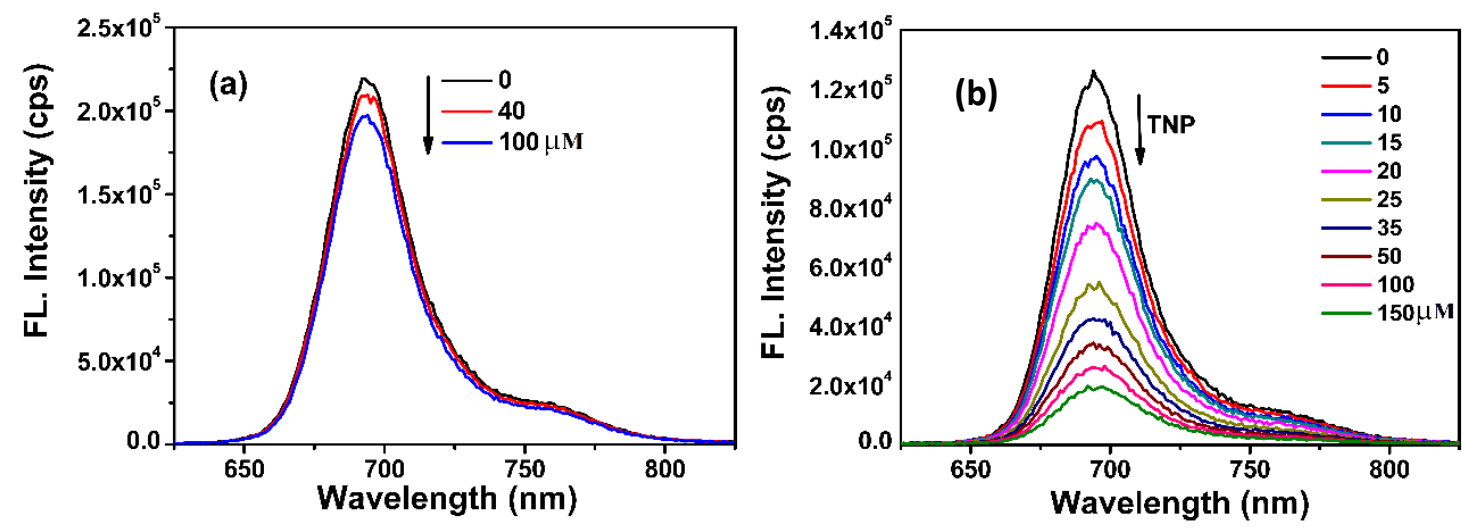

Figure S24. (a) Change in the emission spectra of $\mathrm{ZnPc} 2$ for addition different amounts of river water. (b) Change in the emission spectra of $\mathrm{ZnPc2}$ for addition of different concentrations of TNP in river water.

\section{Morphology}
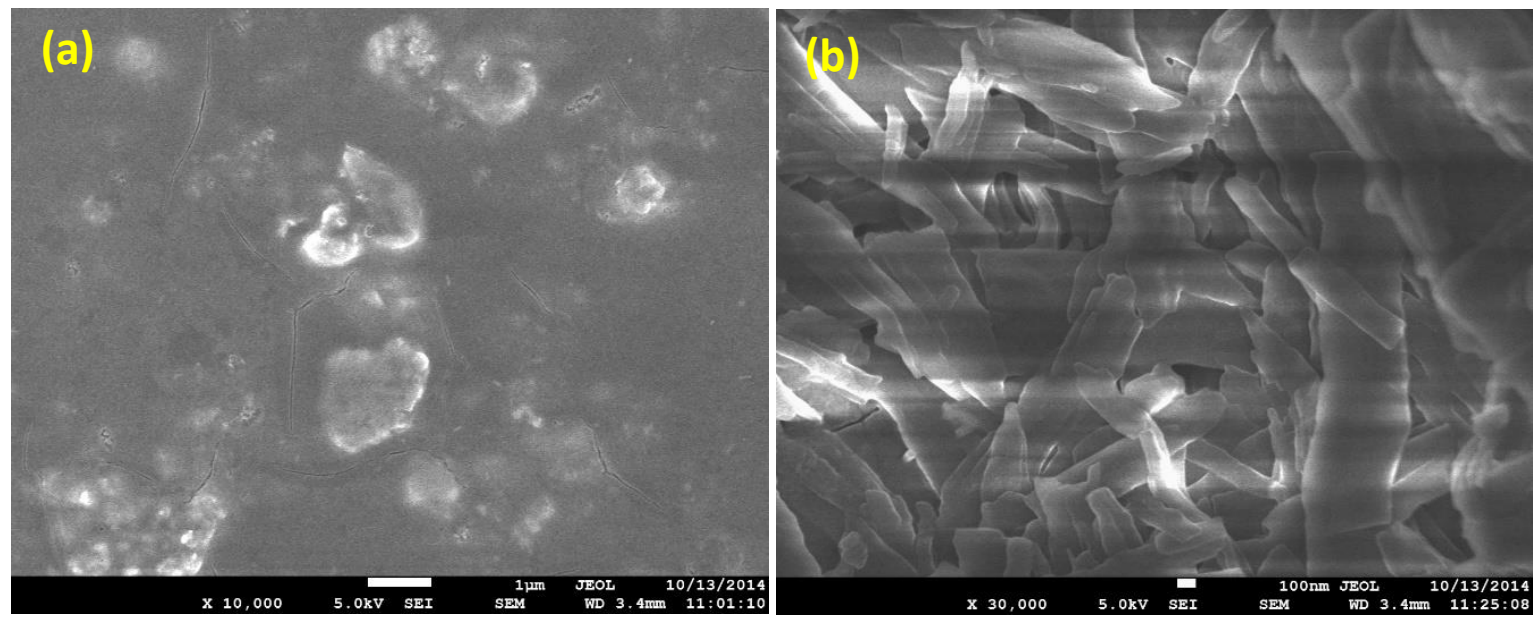

Figure S25. SEM image of ZnPcs films (a) ZnPc1 (b) ZnPc2 
15. Reversibility and recycling study

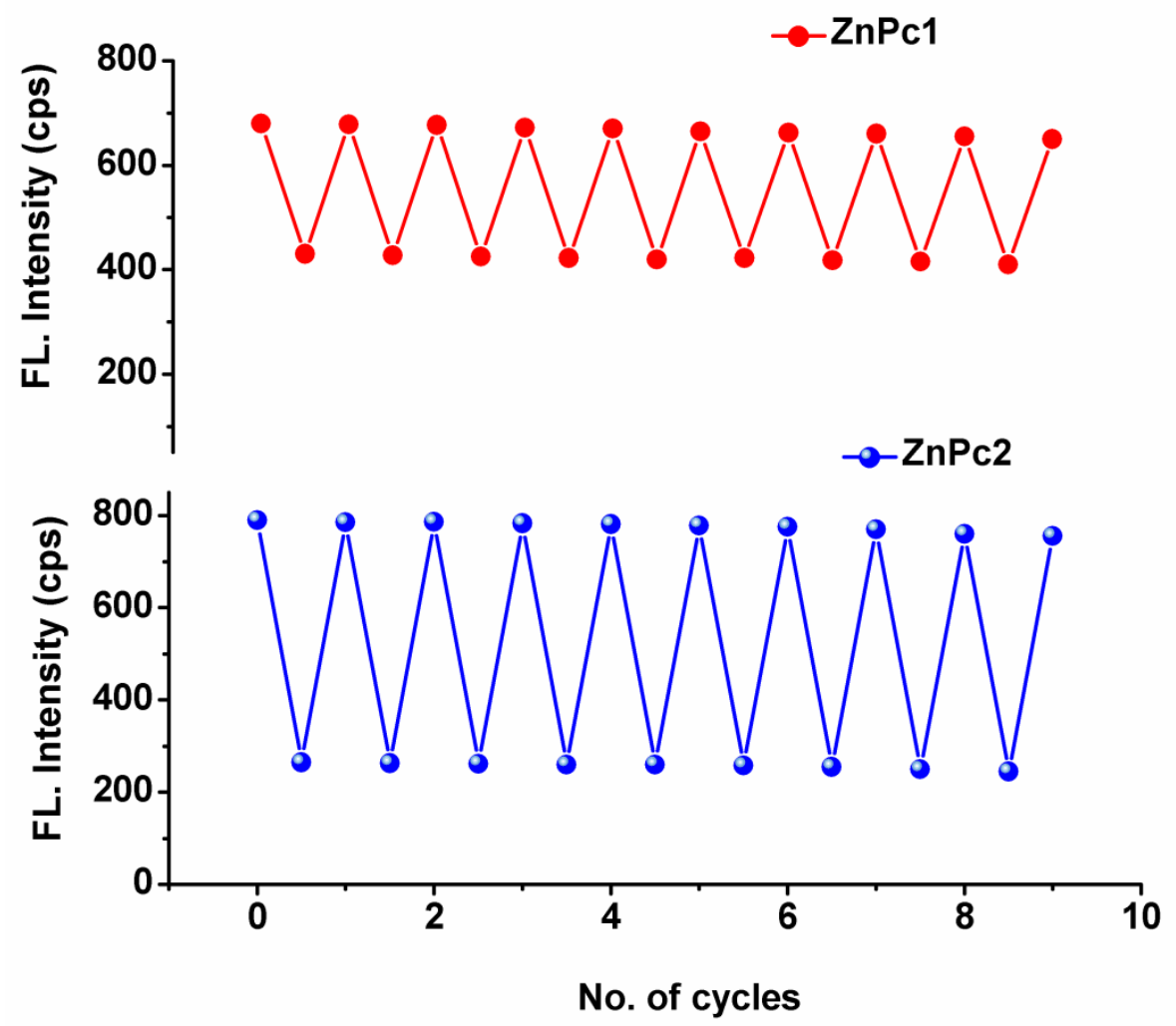

Figure S26. Reversibility and recycling ability of ZnPcs to the saturated vapours of TNP. 